\title{
Heimkehr eines Fragments
}

Seit Herbst 2012 werden am Handschriftenzentrum der Württembergischen Landesbibliothek die "Codices theologici et philosophici in folio", also die ursprünglich dem Bestand der Öffentlichen Bibliothek zugehörigen theologischen und philosophischen Handschriften im Folioformat wissenschaftlich erschlossen. Aufgrund der Größe des Bestandes - insgesamt handelt es sich immerhin um 314 Handschriftensignaturen bzw. ca. 390 Einzelbände - war es notwendig, die Arbeit auf zwei Handschriftenbearbeiter zu verteilen. Beide Projekte werden über Drittmittel finanziert: Die Erschließung der aus dem Mittelalter stammenden Handschriften durch Herrn Dr. Metzger wird von der Deutschen Forschungsgemeinschaft (DFG) unterstützt, während die Verzeichnung der neuzeitlichen Handschriften, die Herr Dr. Kottmann übernommen hat, mit Geldern der Stiftung Kulturgut Baden-Württemberg ermöglicht wurde.

Der Bestand setzt sich vor allem aus lateinischen und deutschsprachigen Handschriften zusammen, die zumeist im Zuge der Säkularisation in die Württembergische Landesbibliothek gekommen sind. Sie umfassen den Zeitraum vom 9. bis zum 20. Jahrhundert und weisen inhaltlich ein äußerst vielfältiges geistesgeschichtliches Spektrum auf.

Zu den aus dem Mittelalter stammenden Handschriften gehört auch eine der wenigen griechischen Handschriften des Fonds, ein Papierkodex, der im zweiten Viertel des 14. Jahrhunderts wohl in Italien entstand und in der WLB unter der Signatur Cod. theol. $2^{\circ} 108$ aufbewahrt wird. Er enthält Werke verschiedener griechischer Autoren, darunter des im 7./8. Jahrhundert wirkenden, aus Damaskus stammenden Theologen und Kirchenvaters Johannes Damascenus, und umfasst im heutigen Zustand 230 Blätter. Im Zuge der Katalogisierung stellte sich heraus, dass mindestens sechs Blätter des ursprünglichen Umfangs als Verlust gelten müssen - ein zwar bedauerlicher, aber keineswegs seltener Befund bei historischen Handschriftenbeständen.

Im Oktober des Jahres 2012 erreichte die Handschriftenabteilung eine Nachricht aus der Bayerischen Staatsbibliothek: Bei der Erschließung der griechischen Handschriften am dortigen Handschriftenzentrum sei ein unter der Signatur Cod. graec. 591 verwahrtes Einzelblatt aufgetaucht, das aus einer Stuttgarter Handschrift, genauer, aus dem eben erwähnten Band mit der Signatur Cod. theol. $2^{\circ} 108$ stamme, die Blattzahl 100 aufweise und wohl um 1840 in die BSB gelangt sei.

Die Überprüfung der Stuttgarter Handschrift ergab, dass Blatt 100 tatsächlich fehlte. Anhand der aus München mitgesandten Scans des Blattes war zudem eindeutig zu erkennen, dass das Münchener Fragment den fehlenden Text aufwies.

Wie genau es zu dem Blattverlust kam, lässt sich nicht mehr rekonstruieren: Vermutlich waren die fehlenden Blätter bereits aus dem Codex entfernt worden, bevor er in den Bestand der Württembergische Landesbibliothek kam - auch dieser Erwerbungszeitpunkt ist ungewiss. Sicher ist, dass die Foliierung, also die Eintragung der Blattzahlen auf den Vorderseiten der Blätter, vorgenommen wurde, bevor die Einzelblätter entfernt wurden. Möglicherweise wurden sie als mittelalterliche griechische Schriftbeispiele verschiedenen Bibliotheken angeboten. Nicht ganz auszuschließen ist daher, dass sich eines Tages auch die übrigen fehlenden Blätter in Fragmenten anderer Handschriftensammlungen finden könnten.

Durch die großzügige Unterstützung und das Entge-genkommen von Seiten der Bayerischen Staatsbibliothek konnte das Fragment im Frühjahr 2013 der Württembergischen Landesbibliothek überreicht werden.

\section{Der Zeitpunkt für die Restitution des Einzelblattes und die Wiedervereinigung mit seinem ursprüngli- chen Überlieferungszusammenhang hätte günstiger nicht sein können: Da das Fragment zu einer der Handschriften gehört, die gerade im Rahmen eines laufenden Erschließungsprojekts neu beschrieben werden, kann es nun in den im Entstehen begrif- fenen Handschriftenkatalog der "Codices theolo- gici" aufgenommen und so zeitnah der Forschung bekanntgemacht werden.}

Kerstin Losert 


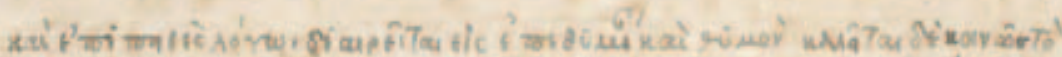

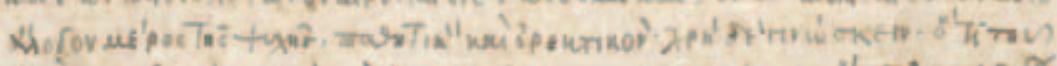

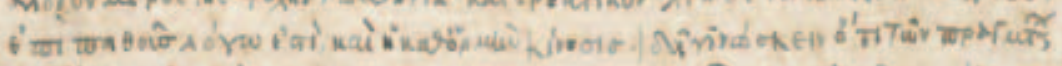

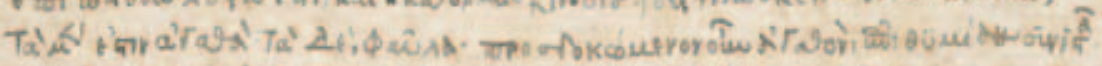

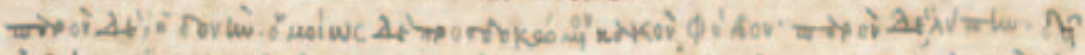

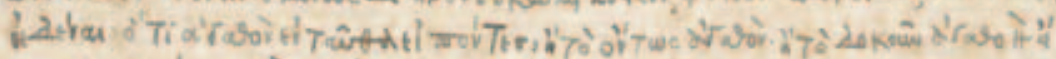

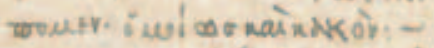
wivita

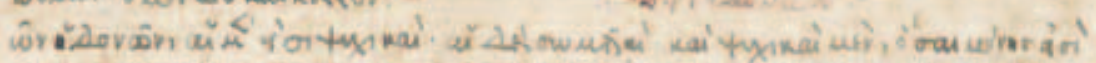

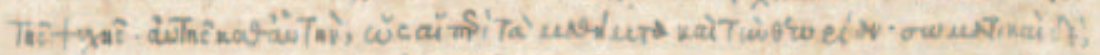

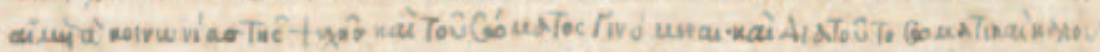

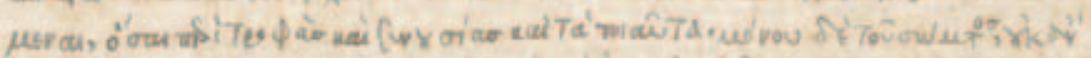

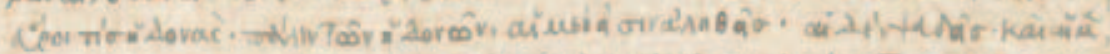

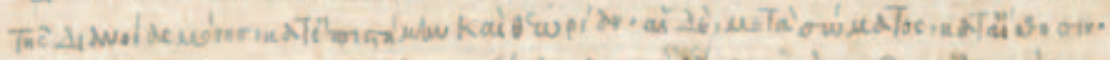

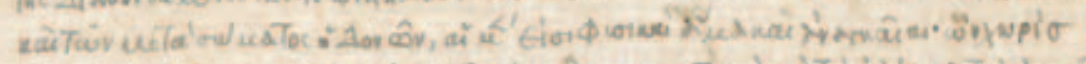

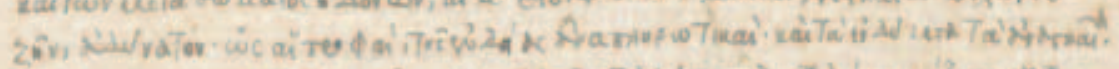

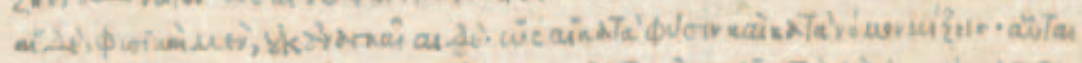

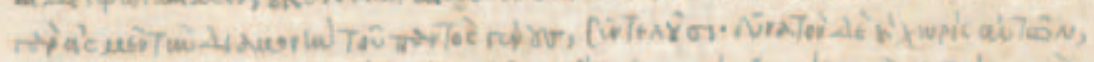

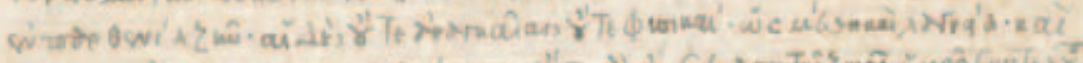

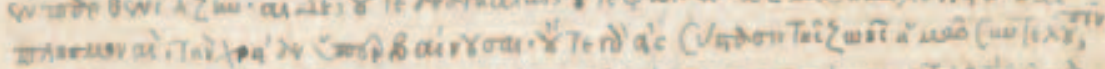

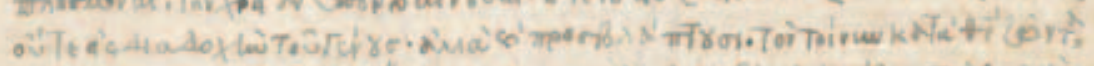

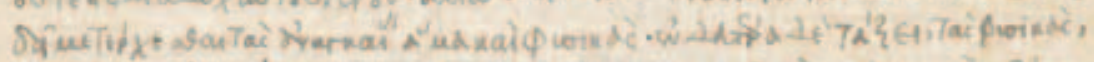

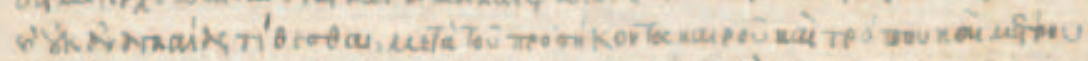

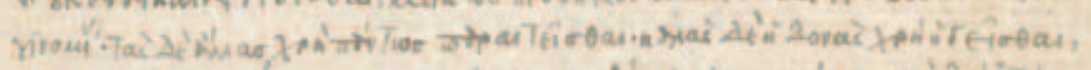

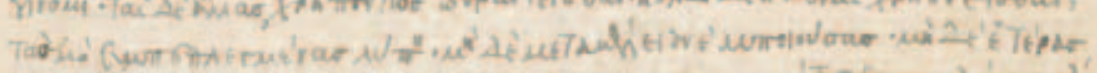

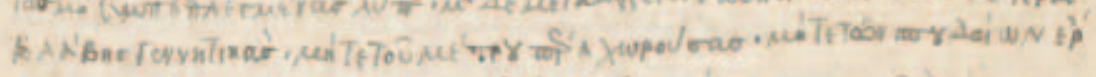

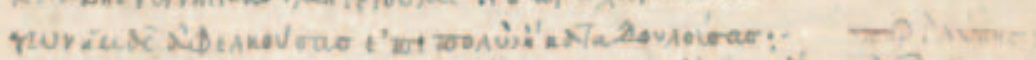

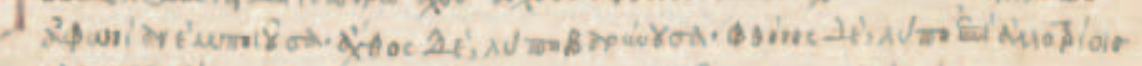

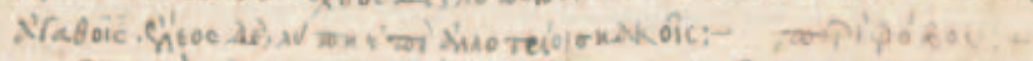

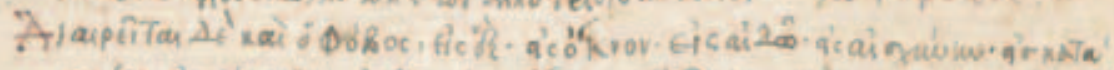

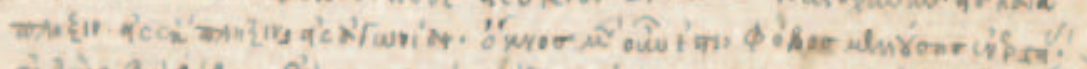

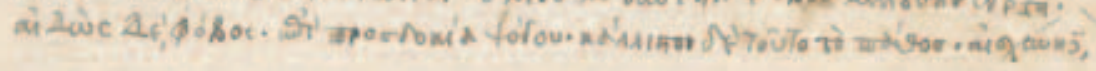

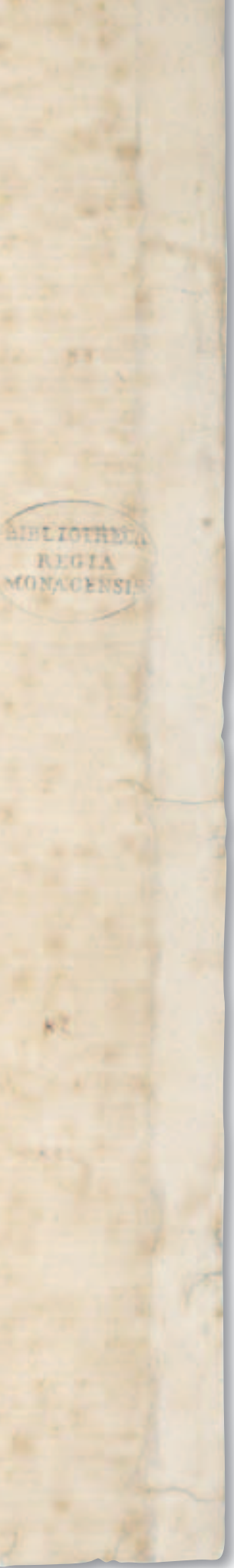

